\title{
Synthesis and Characterization of New Complexes of (N-P-Amino Diphenyl Amine) Amino (2-Hydroxy Phenyl) Acetonitrile Ligand with Some Transition Metal Ions
}

\author{
Ammar Jihad Alabdali \\ (Department of Chemistry, College of Science /Al-Nahrain University, Iraq )
}

\begin{abstract}
The synthesis and characterization of new complexes of $\mathrm{Fe}(\mathrm{II}), \mathrm{Co}(\mathrm{II}), \mathrm{Ni}(\mathrm{II})$ and $\mathrm{Cu}(\mathrm{II})$ with bidentate (N-p-amino diphenyl amine) amino (2-hydroxy phenyl) acetonitrile ligand has been described .The ligand was prepared from 2-hydroxy benzaldehyde and 4-aminodiphenyl amine in the presence of KCN and acidic medium. The complexes were synthesized by treating an ethanolic solution of the ligand with appropriate amount of metal salts [1:2] [M: L] ratio. The complexes were characterized by using metal and elemental analysis, infrared and electronic spectra, molar conductivity, magnetic susceptibility, and mole ratio method. According to the obtained data the probable coordination geometries of Iron, Cobalt, Nickel and Copper in these complexes are octahedral. All complexes were found to be non-electrolyte in absolute ethanol, and the complexes were formulated as $\left[\mathrm{ML}_{2} \mathrm{Cl}_{2}\right]$.
\end{abstract}

Keywords - $\alpha$-aminonitrile, Cobalt, Copper,Complexes,Iron and Nickel.

\section{Introduction}

Strecker reaction [1], is the oldest known synthesis of $\alpha$-aminonitriles since 1850 when Adolph Strecker interacted an aldehyde, an amine and hydrogen cyanide. $\alpha$-aminonitriles synthesis represents one of the simplest and most economical methods for the preparation of $\alpha$-amino acids[2,3] for both laboratory and industrial scales[4]. The synthesis of Nitrogen-containing heterocyclic is important such as thienopyrimidine derivatives which have antibacterial and antifungal activities higher than the corresponding antibacterial ampicillin and antifungal nystatin [5-7]. On the other hand some of the $\alpha$-aminonitrile derivatives like 1-amino4-phenylnaphthalene-2-carbonitrile have been postulated to have high fungistatic activity even stronger than the activity of the commercial fungicide - Kaptan [8].

Moreover, among many other applications, they are readily hydrolyzed to diamines, and diamine compounds are of interest as ligands for Platinum (II) complexes with potential antitumor properties $[9,10]$.

Complexes with ligands $\mathrm{N}_{2}$-type are of interest not only in theoretical but also from a practical point of view. They have found application as antitumor activity [11], antibacterial activity [12] and antiviral activity in agriculture field [13].

To prepare $\alpha$-aminonitriles generally an imine is reacted with a cyanide source. Notable among them are $\mathrm{HCN}$ [14], $\mathrm{KCN}$ [15], $(\mathrm{EtO})_{2} \mathrm{P}(\mathrm{O}) \mathrm{CN}$ [16,17], $\mathrm{Et}_{2} \mathrm{AlCN}$ [18,19], $\mathrm{Bu}_{3} \mathrm{SnCN}$ [20,21], and $\mathrm{Me}_{3} \mathrm{SiCN}_{\text {[22] }}$. Recently, several modifications of the Strecker reaction using catalysts have been reported which includes mesoporous aluminosilicate (Al-MCM-41) [23], lanthanum(III)-binaphthyl disulfonate [24], nanocrystalline magnesium oxide [25], BINOL-phosphoric acid [26,27], $\mathrm{Fe}(\mathrm{Cp})_{2} \mathrm{PF}_{6}$ catalyst [28], Jacobsen's thiourea catalyst [29], $N$-heterocyclic carbine (NHC)-amidate palladium(II) complex [30], $\mathrm{Yb}(\mathrm{OTf})_{3}$-pybox [31], $\mathrm{K}_{2} \mathrm{PdCl}_{4}$ catalyst [32], gallium (III) triflate [33], bisformamides [34], superparamagnetic iron oxide [35], Trimethylsilyl Cyanide - Iodine catalyst [36], Trimethylsilyl Cyanide- $p$-Toluene sulphonic acid [37] , homogeneous and solid supported promoter [38] and $\mathrm{K}_{5} \mathrm{CoW}_{12} \mathrm{O}_{40} \cdot 3 \mathrm{H}_{2} \mathrm{O}$ as heterogeneous catalyst [39].Finally, an efficient and practical method for the Strecker reaction under eco-friendly conditions have been achieved to processed organic reactions in water or ionic liquid in the view of green methodologies [40-43].In this work $\alpha$ aminonitriles have often been used as chelating ligands through two nitrogen atoms in the field of coordination chemistry.This is one of the first studies to reveal a new coordination field of $\alpha$-aminonitrile compounds as ligands and their interactions with transition metal ions.

\section{Experimental}

All the chemicals and solvents used for the synthesis were of reagent grade and were obtained commercially from Fluka company with the exception of $\mathrm{FeCl}_{2} \cdot 4 \mathrm{H}_{2} \mathrm{O} \quad \mathrm{CoCl}_{2} \cdot 6 \mathrm{H}_{2} \mathrm{O}, \mathrm{NiCl}_{2} \cdot 6 \mathrm{H}_{2} \mathrm{O}$ and $\mathrm{CuCl}_{2} \cdot 2 \mathrm{H}_{2} \mathrm{O}$ salts were obtained from British Drug House (BDH). The infrared spectra of the ligand and the complexes were recorded on a Shimadzu (8300) FTIR Spectrophotometer, as CsI disk (ACROS organics COMPANY). Electronic absorption spectra were recorded in the range ( $200-1100$ ) nm on a Shimadzu (UV$1650 \mathrm{Pc}$ ) UV-Vis spectrophotometer in freshly prepared $10^{-3} \mathrm{M}$ in absolute ethanol at room temperature using 
quartz cell $(1.00) \mathrm{cm}$. Atomic absorption technique was used to determine the metal contents of the complexes using a (GBC 933 plus) Atomic absorption spectrophotometer. Molar conductivity was used to measure the conductivity of the complexes at room temperature in freshly prepared $10^{-3} \mathrm{M}$ in absolute ethanol using (WTW inoLab) Digital conductivity meter. Elemental analysis for Carbon, Hydrogen and Nitrogen elements were carried out using EuroEA Elemental Analyzer. Gallen Kamp melting point apparatus was used to determine the melting points of the ligand and the prepared complexes.

\subsection{Preparation method of ( $\mathrm{N}$-p-amino diphenyl amine) amino (2-hydroxy phenyl) acetonitrile ligand [L]:}

The method that adopted for [L] preparation can be described as follows:The 2-hydroxy benzaldehyde $(1 \mathrm{mmol})$ was added to $(20 \mathrm{ml})$ glacial acetic acid, $p$-toluene sulphonic acid was added in very small portion as catalyst, followed by addition of $(1 \mathrm{mmol}) p$-amino diphenyl amine. The $\mathrm{pH}$ was adjusted to about 4 by addition of concentrated sulfuric acid drop wise to obtain Schiff base which stirred for 15 min. Potassium cyanide (2 mmol) was added to the mixture and kept under stirring for 4 days. The reaction mixture was poured into ice and then made slightly alkaline with ammonium hydroxide solution. The desired solid precipitate which formed was filtered, washed with water and air dried.

The presence of nitrile group in the prepared $\alpha$-aminonitrile was indicated by treating few amount of the sample with $10 \%$ sodium hydroxide solution, the liberation of ammonia after hydrolysis of nitrile group was detected by wet red litmus paper. Purity of the obtained compound was checked by TLC, using chloroform and ethyl acetate $(1: 1)$ as eluent. The product color was dark green and the yield percentage was $(88 \%)$ and the melting point was $(78 \mathrm{~d}){ }^{0} \mathrm{C}$. The reaction was clarified below:

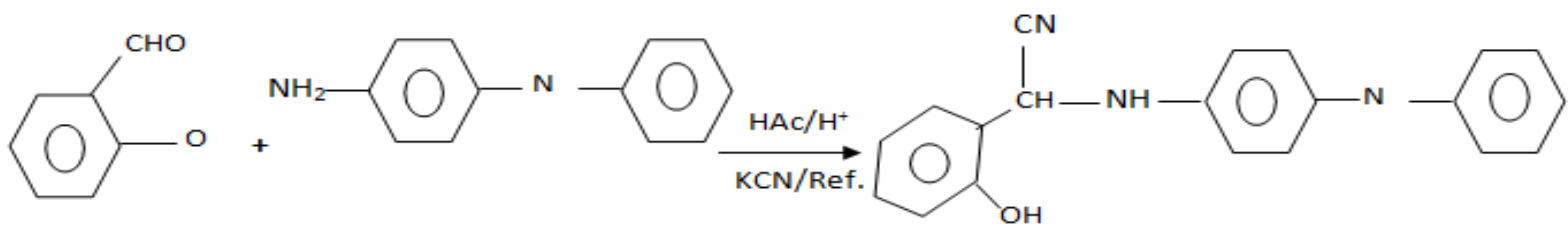

\subsection{Preparation method of metal complexes:}

The complexes $\left[\mathrm{ML}_{2} \mathrm{Cl}_{2}\right]$ have been prepared by the reaction of $2 \mathrm{mmol}(0.630 \mathrm{gm})$ of $\mathrm{L}$ with $1 \mathrm{mmol}$ of metal chloride $\left(0.199 \mathrm{gm}, 0.238 \mathrm{gm}, 0.238 \mathrm{gm}\right.$ and $0.171 \mathrm{gm}$ for $\mathrm{FeCl}_{2} \cdot 4 \mathrm{H}_{2} \mathrm{O}, \mathrm{CoCl}_{2} \cdot 6 \mathrm{H}_{2} \mathrm{O}, \mathrm{NiCl}_{2} .6 \mathrm{H}_{2} \mathrm{O}$ and $\mathrm{CuCl}_{2} \cdot 2 \mathrm{H}_{2} \mathrm{O}$ respectively) dissolved in $(20 \mathrm{ml})$ absolute ethanol and refluxed with stirring under anhydrous conditions for 4 hours. The obtained complexes were collected after evaporation of ethanol and triturated with petroleum ether $\left(60-80{ }^{\circ} \mathrm{C}\right)$ then filtered . The products were left in the desiccators to be dried under $\mathrm{P}_{2} \mathrm{O}_{5}$. The general reaction was clarified below:

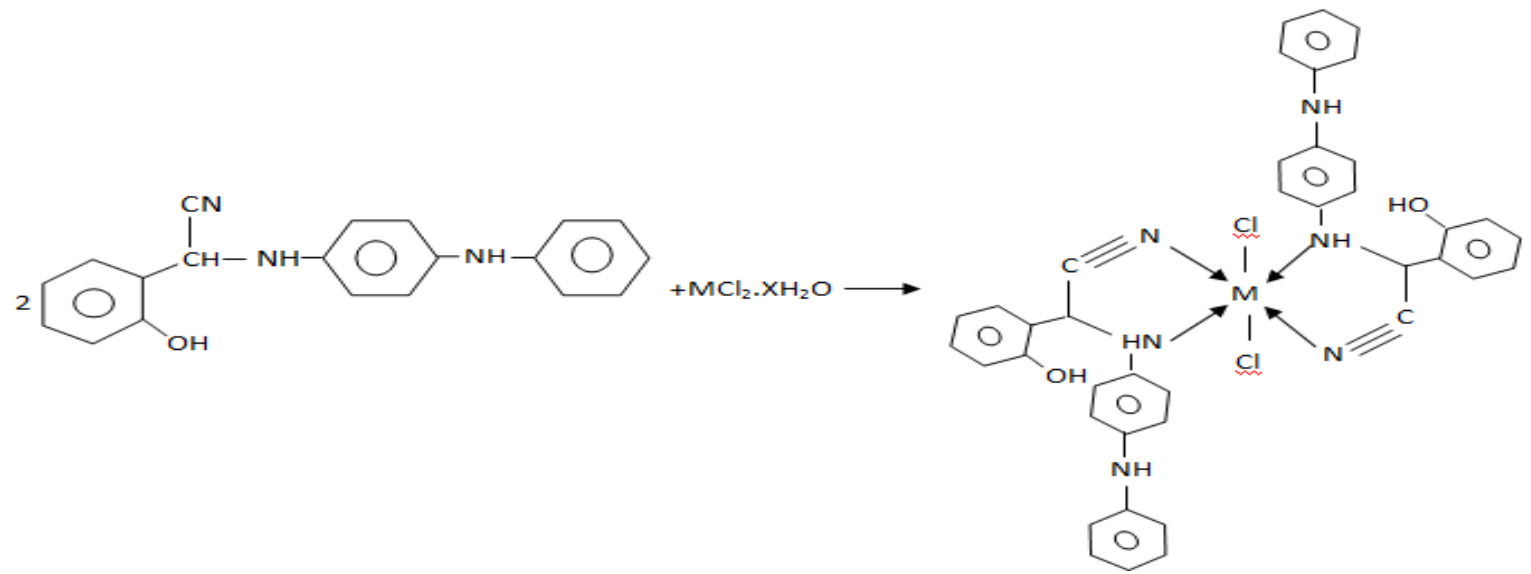

\section{Results And Discussion}

All the compounds reported in this work are presented in table (1) which illustrated physical properties along with their molar conductivity at room temperature. Metal and elemental analyses of all compounds are represented in table (2). The ligand (L) was characterized by elemental analysis and infrared spectral data. $\alpha$ aminonitrile compounds are bifunctional like amino acids but with nitrile group instead of carboxylic, (L) compound considered trifunctional due to the presence of hydroxyl group in benzene ring which could be analogue of serine amino acid .Therefore the expected coordination type of $(\mathrm{L})$ is tridentate which resembles the behavior of some amino acid like histidine [44], but the obtained complexes were characterized as bidentate $\left(\mathrm{N}_{2}\right.$ - type $)$. The complexes have been prepared under anhydrous conditions to avoid any hydrolysis of 
nitrile group to amide due to the presence of water molecules and metal ion [45].when organic molecules are coordinated to metal cations in organo-metallic or coordination compounds, they become susceptible to nucleophilic attack like water molecules which cause hydrolysis of nitrile into amide and this could be avoided under anhydrous condition [46]. In spite of using anhydrous conditions complexation of zinc metal ion with (L) was not successful and dragged into hydrolysis of nitrile group to amid which clearly characterized in FTIR chart at $1656 \mathrm{~cm}^{-1}$. Therefore the complex dose not mentioned. These prepared complexes were stable in the solid state and were characterized by the usual methods; IR and UV- Visible spectroscopy, Molar conductivity, metal and elemental analysis, magnetic susceptibility and mole ratio.

On the basis of the characterization methods it was suggested that all complexes probably have octahedral structure with coordination number 6 that includes two atoms of coordinated chlorides and without coordinated or lattice water. The conductivity values for the complexes of $\left(10^{-3} \mathrm{M}\right)$ in absolute ethanol were recorded in rang (11-16) indicating that the non-electrolytic nature of the complexes [47]. Mole ratio method was used to determine the ratio of metal ion to ligand for the complexes at $\lambda_{\max }\left(\lambda_{\max }=881 \mathrm{~nm}\right.$ for $\left[\mathrm{FeL}_{2} \mathrm{Cl}_{2}\right], \lambda$ max $=566 \mathrm{~nm}$ for $\left[\mathrm{CoL}_{2} \mathrm{Cl}_{2}\right]$ and $\lambda_{\max }=680 \mathrm{~nm}$ for $\left.\left[\mathrm{CuL}_{2} \mathrm{Cl}_{2}\right]\right)$ in alcoholic solutions.

\subsection{Infrared spectroscopy:}

The infrared spectral data of $[\mathrm{L}]$ in table(3) showed some characteristic bands related to $\alpha$ aminonitriles ; Like $2240-2260 \mathrm{~cm}^{-1}$ which could be attributed to $\mathrm{C} \equiv \mathrm{N}$ group[48]. A red shift of the range 35-95 $\mathrm{cm}^{-1}$ was observed for $\mathrm{C} \equiv \mathrm{N}$ stretching vibration on coordination due to the decrease of bond order as result of metal nitrogen bond formation. A red shift of $\mathrm{N}-\mathrm{H}$ group on complexes could not be detected due to the presence of O-H group which usually over shade it. On the other hand the spectrum of the complexes showed new bands around 451-488 $\mathrm{cm}^{-1}$ and 376-393 $\mathrm{cm}^{-1}$ due to $v \mathrm{M}-\mathrm{N}$ and $v \mathrm{M}-\mathrm{Cl}$ respectively [49].

\subsection{Ultra violet - visible spectroscopy:}

The data of ultra violate spectra of the ligand and the complexes and the suggested structures are listed in table(4). The ligand showed two absorption bands in the region $39840 \mathrm{~cm}^{-1}$ and $32051 \mathrm{~cm}^{-1}$ corresponding to $\left(\pi \rightarrow^{*} \pi\right)$ and $\left(n \rightarrow^{*} \pi\right)$ transitions respectively. Shifting has been observed in ligand field after complexation and new bands were observed due to the presence of metal ions in the complexes.

The electronic spectrum of Iron (II) complex showed one broad band at $11350 \mathrm{~cm}^{-1}$ due to (d-d) transitions. A band at $26666 \mathrm{~cm}^{-1}$ in the spectrum represented the $(\mathrm{L} \rightarrow \mathrm{M})$ charge transfer for the $\left[\mathrm{FeL}_{2} \mathrm{Cl}_{2}\right]$ complex [50]. The effective magnetic moment was (5.19 BM) which is typical for distorted octahedral [51]. The electronic spectrum of Nickel (II) complex showed three (d-d) transition bands at $22421 \mathrm{~cm}^{-1}, 20080 \mathrm{~cm}^{-1}$ and $10493 \mathrm{~cm}^{-1}$ corresponding to ${ }^{3} \mathrm{~A}_{2 \mathrm{~g}}(\mathrm{~F}) \rightarrow{ }^{3} \mathrm{~T}_{1 \mathrm{~g}}(\mathrm{P})\left(U_{3}\right),{ }^{3} \mathrm{~A}_{2 \mathrm{~g}}(\mathrm{~F}) \rightarrow{ }^{3} \mathrm{~T}_{1 \mathrm{~g}}(\mathrm{~F})\left(U_{2}\right)$ and ${ }^{3} \mathrm{~A}_{2 \mathrm{~g}}(\mathrm{~F}) \rightarrow{ }^{3} \mathrm{~T}_{2 \mathrm{~g}}(\mathrm{~F})$ $\left(U_{1}\right)$ transitions respectively. Which suggested mostly octahedral geometry. The magnetic moment value for the Nickel (II) complex was found to be (2.90 B.M) [51, 52]. A peak of $\left[\mathrm{NiL}_{2} \mathrm{Cl}_{2}\right]$ complex spectrum appeared at $25575 \mathrm{~cm}^{-1}$ which represented to the $(\mathrm{L} \rightarrow \mathrm{M})$ charge transition band[50].Cobalt(II) complex has magnetic moments value (3.78 B.M) which agreed with the expected value for the high spin Cobalt (II) ion in octahedral environment[51,53]. The electronic spectrum of Cobalt (II) complex showed two main bands at $17667 \mathrm{~cm}^{-1}$ and $16611 \mathrm{~cm}^{-1}$. These two bands are assigned to ${ }^{4} \mathrm{~T}_{1 \mathrm{~g}}(\mathrm{~F}) \rightarrow{ }^{4} \mathrm{~T}_{1 \mathrm{~g}}(\mathrm{P})\left(U_{3}\right)$ and ${ }^{4} \mathrm{~T}_{1 \mathrm{~g}}(\mathrm{~F}) \rightarrow{ }^{4} \mathrm{~A}_{2 \mathrm{~g}}(\mathrm{~F})\left(U_{2}\right)$ transitions respectively. The $\left(U_{1}\right)$ transition is expected to appear at large wave length. Thus it could not be observed, therefore it was calculated. The observed transitions are consistent with an octahedral geometry. A band of $\left[\mathrm{CoL}_{2} \mathrm{Cl}_{2}\right]$ complex spectrum appeared at $25445 \mathrm{~cm}^{-1}$ represented to the ( $\mathrm{L} \rightarrow \mathrm{M})$ charge transition band [50].The electronic spectrum of Copper (II) complex showed two bands. These two bands appeared at $14705 \mathrm{~cm}^{-1}$ and $19230 \mathrm{~cm}^{-1}$ ascribed to the (d-d) transitions. Another band appeared above $26666 \mathrm{~cm}^{-1}$ represented to the $(\mathrm{L} \rightarrow \mathrm{M})$ charge transition [50]. The obtained value of the effective magnetic moment (1.82BM) is typical for distorted octahedral $\mathrm{Cu}(\mathrm{II})$ chelates $[51,53]$.

Table (1) Physical properties of (L) and its metal complexes with their conductivity values

\begin{tabular}{|c|c|c|c|c|}
\hline Compound & Color & M.P. ${ }^{\circ} \mathrm{C}$ & Yield \% & $\Omega^{-1} \mathrm{~cm}^{2} \mathrm{~mol}^{-1}$ \\
\hline $\mathrm{L}$ & Dark green & $78 \mathrm{~d}$. & 95.23 & $\cdots--$ \\
\hline$\left[\mathrm{FeL}_{2} \mathrm{Cl}_{2}\right]$ & brown green & $121-123$ & 79.36 & 16 \\
\hline$\left[\mathrm{CoL}_{2} \mathrm{Cl}_{2}\right]$ & Brown & $99-102$ & 81.57 & 12 \\
\hline$\left[\mathrm{Ni}_{2} \mathrm{Cl}_{2}\right]$ & Light green & $223-225$ & 84.25 & 14 \\
\hline$\left[\mathrm{CuL}_{2} \mathrm{Cl}_{2}\right]$ & Dark blue & $117-120$ & 83.77 & 11 \\
\hline
\end{tabular}


Table (2) Analytical data of (L) and its Complexes

\begin{tabular}{|c|c|c|c|c|}
\hline \multirow{2}{*}{$\begin{array}{c}\text { Formula } \\
\text { M.Wt. }(\mathrm{g} / \mathrm{mol})\end{array}$} & \multicolumn{4}{|c|}{$\begin{array}{c}\text { Elemental And Metal Analysis Calculated } \\
\text { (Found) }\end{array}$} \\
\cline { 2 - 5 } & $\mathrm{C} \%$ & $\mathrm{H} \%$ & $\mathrm{~N} \%$ & $\mathrm{M} \%$ \\
\hline $\mathrm{L}$ & 76.19 & 5.39 & 13.33 & $\ldots .$. \\
315 & $(76.03)$ & $(5.38)$ & $(13.21)$ & \\
\hline$\left[\mathrm{FeL}_{2} \mathrm{Cl}_{2}\right]$ & 63.42 & 4.49 & 11.10 & 7.37 \\
756.8 & $(60.93)$ & $(4.22)$ & $(10.85)$ & $(7.00)$ \\
\hline$\left[\mathrm{CoL}_{2} \mathrm{Cl}_{2}\right]$ & 63.16 & 4.47 & 11.05 & 7.75 \\
759.9 & $(62.86)$ & $(4.31)$ & $(10.77)$ & $(7.44)$ \\
\hline$\left[\mathrm{NiL}_{2} \mathrm{Cl}_{2}\right]$ & 63.18 & 4.47 & 11.05 & 7.72 \\
759.7 & $(62.96)$ & $(4.22)$ & $(10.72)$ & $(7.53)$ \\
\hline$\left[\mathrm{CuL}_{2} \mathrm{Cl}_{2}\right]$ & 62.78 & 4.45 & 10.98 & 8.31 \\
764.5 & $(62.66)$ & $(4.41)$ & $(10.77)$ & $(8.00)$ \\
\hline
\end{tabular}

Table (3) The characteristic bands of FTIR spectra of the ligand and its metal complexes in $\left(\mathrm{cm}^{-1}\right)$

\begin{tabular}{|c|c|c|c|c|c|c|c|c|c|}
\hline \multirow[t]{2}{*}{ Compound } & \multirow{2}{*}{$\begin{array}{l}v \mathrm{O}-\mathrm{H} \mathrm{cm}^{-1} \\
v \mathrm{~N}-\mathrm{H} \mathrm{cm}^{-1}\end{array}$} & \multirow{2}{*}{$\begin{array}{l}v \mathrm{C}-\mathrm{H} \mathrm{cm}^{-1} \\
\text { Aromatic }\end{array}$} & \multirow{2}{*}{$\begin{array}{l}v \mathrm{C}-\mathrm{H} \mathrm{cm}^{-1} \\
\text { Aliphatic }\end{array}$} & \multirow{2}{*}{$\begin{array}{l}v \mathrm{C} \equiv \mathrm{N} \\
\text { Nitrile }\end{array}$} & \multirow{2}{*}{$\begin{array}{l}\text { Aromaticit } \\
\mathrm{y}\end{array}$} & \multicolumn{2}{|c|}{$\begin{array}{c}\text { סC-H out of plane } \\
\text { deformation }\end{array}$} & \multirow[t]{2}{*}{$v \mathrm{M}-\mathrm{N}$} & \multirow[t]{2}{*}{$v \mathrm{M}-\mathrm{Cl}$} \\
\hline & & & & & & ortho & Para & & \\
\hline $\mathrm{L}$ & 3356 & 3053 & 2930 & 2210 & 1595,1510 & 750 & 827 & -...- & - \\
\hline$\left[\mathrm{FeL}_{2} \mathrm{Cl}_{2}\right]$ & 3380 & 3056 & 2923 & 2115 & 1595,1504 & 750 & 831 & 451 & 380 \\
\hline$\left[\mathrm{CoL}_{2} \mathrm{Cl}_{2}\right]$ & 3334 & 3075 & 2936 & 2172 & 1595,1506 & 752 & 829 & 488 & 376 \\
\hline$\left[\mathrm{NiL}_{2} \mathrm{Cl}_{2}\right]$ & 3396 v.bro & Obscured & 2960 & 2175 & 1614,1512 & 752 & 880 & 474 & 393 \\
\hline $\left.\mathrm{CuL}_{2} \mathrm{Cl}_{2}\right]$ & 3400 & 3078 & 2940 & 2165 & 1578,1512 & 754 & 850 & 480 & 382 \\
\hline
\end{tabular}

Table (4) Electronic spectra in absolute ethanol for the (L) and its metal complexes.

\begin{tabular}{|c|c|c|c|c|c|c|c|c|c|c|}
\hline Comp. & $\lambda \mathrm{nm}$ & $v \mathrm{~cm}^{-1}$ & Transition & $\begin{array}{c}\mathrm{B}^{0} \\
\mathrm{~cm}^{-1}\end{array}$ & $\begin{array}{l}\mathrm{B}^{-} \\
\mathrm{cm}^{-1}\end{array}$ & $\beta$ & $\mathrm{Dq} / \mathrm{B}^{-}$ & $\begin{array}{l}10 \mathrm{Dq} \\
\mathrm{cm}^{-1}\end{array}$ & $\begin{array}{l}15 \mathrm{~B}^{-} \\
\mathrm{cm}^{-1}\end{array}$ & $\begin{array}{c}\text { Suggested } \\
\text { structure }\end{array}$ \\
\hline L & $\begin{array}{l}251 \\
312\end{array}$ & $\begin{array}{l}39840 \\
32051\end{array}$ & $\begin{array}{l}\pi \rightarrow{ }^{*} \pi \\
n \rightarrow{ }^{*} \pi\end{array}$ & & & & & & & \\
\hline$\left[\mathrm{FeL}_{2} \mathrm{Cl}_{2}\right]$ & $\begin{array}{l}233 \\
301 \\
375 \\
881\end{array}$ & $\begin{array}{l}36232 \\
33223 \\
26666 \\
11350\end{array}$ & $\begin{array}{c}\text { Ligand Field } \\
\text { Ligand Field } \\
\text { C.T } \\
{ }^{5} \mathrm{~T}_{2 \mathrm{~g}} \rightarrow{ }^{5} \mathrm{E}_{\mathrm{z}}\end{array}$ & & & & & & & $\begin{array}{c}\text { distorted } \\
\text { O.h }\end{array}$ \\
\hline$\left[\mathrm{CoL}_{2} \mathrm{Cl}_{2}\right]$ & $\begin{array}{c}211 \\
289 \\
393 \\
566 \mathrm{bro} . \\
602 \mathrm{sh} . \\
1268\end{array}$ & \begin{tabular}{|c|}
47393 \\
34602 \\
25445 \\
17667 \\
16611 \\
7881 (cal)
\end{tabular} & $\begin{array}{c}\text { Ligand Field } \\
\text { Ligand Field } \\
\text { C.T } \\
{ }^{4} \mathrm{~T}_{1 \mathrm{~g}}(\mathrm{~F}) \rightarrow{ }^{4} \mathrm{~T}_{1 \mathrm{~g}}(\mathrm{P}) \\
{ }^{4} \mathrm{~T}_{1 \mathrm{~g}}(\mathrm{~F}) \rightarrow{ }^{4} \mathrm{~A}_{2 \mathrm{~g}}(\mathrm{~F}) \\
{ }^{4} \mathrm{~T}_{1 \mathrm{~g}}(\mathrm{~F}) \rightarrow{ }^{4} \mathrm{~T}_{2 \mathrm{~g}}(\mathrm{~F})\end{array}$ & 971 & 709.2 & 0.73 & 1.23 & 8730 & 10638 & O.h \\
\hline$\left[\mathrm{NiL}_{2} \mathrm{Cl}_{2}\right]$ & $\begin{array}{c}263 \\
293 \\
391 \\
446 \\
498 \text { mean } \\
953\end{array}$ & $\begin{array}{l}38022 \\
34129 \\
25575 \\
22421 \\
20080 \\
10493\end{array}$ & $\begin{array}{c}\text { Ligand Field } \\
\text { Ligand Field } \\
\text { C.T } \\
{ }^{3} \mathrm{~A}_{2 \xi}(\mathrm{F}) \rightarrow{ }^{3} \mathrm{~T}_{1 \mathrm{~g}}(\mathrm{P}) \\
{ }^{3} \mathrm{~A}_{2 \mathrm{~g}}(\mathrm{~F}) \rightarrow{ }^{3} \mathrm{~T}_{\mathrm{gg}}(\mathrm{F}) \\
{ }^{3} \mathrm{~A}_{2 \mathrm{~g}}(\mathrm{~F}) \rightarrow{ }^{3} \mathrm{~T}_{2 \mathrm{~g}}(\mathrm{~F})\end{array}$ & 1030 & 734.8 & 0.71 & 1.43 & 10493 & 11022 & O.h \\
\hline$\left[\mathrm{CuL}_{2} \mathrm{Cl}_{2}\right]$ & $\begin{array}{c}247 \\
295 \\
375 \\
521 \mathrm{sh} . \\
680 \mathrm{bro} .\end{array}$ & $\begin{array}{l}39370 \\
33898 \\
26666 \\
19230 \\
14705\end{array}$ & $\begin{array}{c}\text { Ligand Field } \\
\text { Ligand Field } \\
\text { C.T } \\
{ }^{2} \mathrm{~B}_{1 \mathrm{~g}} \rightarrow{ }^{2} \mathrm{~B}_{2 \mathrm{~g}} \\
{ }^{2} \mathrm{~B}_{1 \mathrm{~g}} \rightarrow{ }^{2} \mathrm{E}_{\mathrm{g}}\end{array}$ & & & & & & & $\begin{array}{c}\text { distorted } \\
\text { O.h }\end{array}$ \\
\hline
\end{tabular}




\section{References}

[1] A.Strecker, Ueber die künstliche Bildung der Milchsäure und einen neuen dem glycocoll homologen , Ann.Chem. Pharm., 75,1850,27-45.

[2] K Harada, Asymmetric Synthesis of $\alpha$-Amino Acids by the Strecker Synthesis, Nature, 200,1963,1201.

[3] D.A.Evans , A.E.Weber, Asymmetric Glycine Enolate Aldol Reactions: Synthesis of Cyclosporine's Unusual Amino Acid MeBmt, J. Am. Chem. Soc., 108,1986,6757.

[4] H,Groger, Catalytic enantioselective Strecker reactions and analogous syntheses, Chem.Rev., 103,2003,2795-2827.

[5] H.B.Mosharef, R.Mizanur, H. Kamrul and A.Mohammad, Synthesis and antimicrobial evaluation of some new thienopyrimidine derivatives, Acta Pharm., 56 ,2006, 441-450.

[6] S.S.R.Nitinkumar, and A.M.Imtiyaz, Synthesis and antimicrobial activity of some novel thienopyrimidines and triazolothienopyrimidines,J. Chem. Sci., 121(3),2009,301-30

[7] H.B.Mosharef, M.M.Rahman and I.Imjamul, Synthesis, Characterization and Antimicrobial Evaluation of Some Arylidenehydrazonofuropyrimidines and Thienopyrimidines, Pak. J. Sci. Ind. Res. , 52 (4),2009,180-185.

[8] B.Kozik, Z.J. Burgiel, J.J. Sepiol, J.Wilamowski, M.K.Luczynski, M.Gora, Synthesis and fungistatic activity of aryl-substituted naphthalene- and indene-2-carbonitriles, Enviromental biotechnology, 2 (1),2006,20-25.

[9] Z.Guo and P.J.Sadler, 1999, metals in medicine, Angew. Chem. Int. Ed., 38,1999,1512-1531.

[10] S.Rafique, M.Idrees, A.Nasim, H.Akbar and A.Athar, Transition metal complexes as potential therapeutic agents, Biotechnol. Mol. Biol. Rev., 5 (2),2010,38-45.

[11] A.S.Abu-Surrah et al, Palladium - based chemotherapeutic agents: Routs toward complexes with good anti tumor activity, Cancer therapy, 6,2008,1-10.

[12] S.Thoha,S.S. Karki and B.R.Bhukya, Sythesis, characterization and antibacterial activity of some novel mononuclear Ru(II) complexes, Inter.J.Pharm. Pharmaceutical science, 1(2), 2009, 62-70.

[13] S.N.Thakur, K.S.Yadav, N.P.Singh and H.S.Yadav, Template synthesis and characterization of oxovanadium (IV) complexes with tetraaza macrocyclic ligands and their activity on potato virus X, J.Iran. Chem. Soc. 5(2) ,2008,328-335.

[14] N.Kato, M.Suzuki, M.Kanai, M.Shibasaki, Catalytic enantioselective Strpecker reaction of ketimines using catalytic amount of TMSCN and stoichiometric amount of HCN, Tetrahedron Lett. , 45,2004,3153-3155.

[15] E.Gruszecka, M.Soroka, P.Mastalerz, Preparation of D,L-phosphinothricin by Strecker reaction, Polish J. Chem. , 53,1979,937939.

[16] E.Reimann and W.Dammertz, Bicyclic a-amino acids. IV: Synthesis of 3-(1-tetralinyl)- and 3-(5,6,7,8-tetrahydro-5quinolinyl)alanine, Arch. Pharm., 316,1983,297-302.

[17] S.Harusawa, Y.Hamada and T.Shioiri, New methods and reagents in organic synthesis. Diethyl phosphorocyanidate (DEPC). A novel reagent for the classical Strecker's $\alpha$-aminonitrile synthesis, Tetrahedron Lett., 48,1979,4663-4666.

[18] FA Davis, KR Prasad and PJ Carroll, Asymmetric synthesis of polyhydroxy $\alpha$-amino acids with the sulfinimine-mediated asymmetric Strecker reaction: 2-amino 2-deoxy L-xylono-1,5-lactone (Polyoxamic acid lactone), J. Org. Chem. , 67,2002,78027806.

[19] P.Kaur, S.Pindi, W.Wever, T.Rajale and G.Li, Asymmetric catalytic Strecker reaction of N-phosphonyl imines with Et2AlCN using amino alcohols and BINOLs as catalysts, Chem. Commun., 46,2010,4330-4332.

[20] Z.Xie, G.Li, G.Zhao and J.Wang, Strecker-type reaction catalyzed by carboxylic acids in aqueous media, Synthesis , $12,2009,2035-2039$.

[21] H.Ishitani, S.Komiyama, Y.Hasegawa and S.Kobayashi, Catalytic asymmetric Strecker synthesis. Preparation of enantiomerically pure $\alpha$-amino acid derivatives from aldimines and tributyltin cyanide or achiral aldehydes, amines, and hydrogen cyanide using a chiral zirconium catalyst, Am. Chem. Soc., 122,2000,762

[22] D.Prajapati, R.C.Boruah, J.S.Sandbu and J.N.Baruah, A new synthesis of $\alpha$-aminonitriles using cyanotrimethylsilane, Indian J. Chem. ,23B ,1984, 853-854

[23] K.Iwanami, H.Seo, J.Choi, T.Sakakura and H.Yasuda, Al-MCM-41 catalyzed three-component Strecker-type synthesis of $\alpha$ aminonitriles, Tetrahedron, 66,2010,1898-1901.

[24] M.Hatano, Y.Hattori, Y.Furuya and K.Ishihara, Chiral lanthanum(III)-binaphthyldisulfonate complexes for catalytic enantioselective Strecker reaction,Org. Lett., 11,2009,2321-2324.

[25] ML Kantam,K.Mahendar, B.Sreedhar and BM Choudary, Synthesis of $\alpha$-amino nitriles through Strecker reaction of aldimines and ketoimines by using nanocrystalline magnesium oxide, Tetrahedron , 64,2008,3351-3360.

[26] L.Simon and JM Goodman, Mechanism of BINOL-phosphoric acid-catalyzed Strecker reaction of benzyl imines, J. Am. Chem. Soc., 131,2009,4070-4077.

[27] G.Zhang, D.Zheng, J.Nie, T.Wang and J.Ma, Bronsted acid-catalyzed efficient Strecker reaction of ketones, amines and trimethylsilyl cyanide, Org. Biomol. Chem.,8,2010,1399-1405.

[28] NH Khan, S.Agrawal, R.Kureshy, SHR Abdi, S.Singh, E.Suresh and RV Jasra, Fe(Cp)2PF6 catalyzed efficient Strecker reactions of ketones and aldehydes under solvent-free conditions, Tetrahedron Lett. , 49,2008,640-644.

[29] SC Pan and B.List, Catalytic asymmetric three-component acyl-Strecker reaction, Org. Lett., 9,2007,1149-1151.

[30] J.Jarusiewicz, Y.Choe, K.Yoo, CP Park and KW Jung, Efficient three-component Strecker reaction of aldehydes/ketones via NHC-amidate palladium(II) complex catalysis, J. Org. Chem. , 74,2009,2873-2876.

[31] B.Karimi, A.Maleki, D.Elhamifar, JH Clark and AJ Hunt, Self-assembled organic-inorganic hybrid silica with ionic liquid framework: a novel support for the catalytic enantioselective Strecker reaction of imines using Yb(OTf)3-pybox catalyst, Chem.Commun.,46,2010,6947-6949.

[32] B.Karmakar and J.Banerji, K2PdCl4 catalyzed efficient multicomponent synthesis of $\alpha$-aminonitriles in aqueous media,Tetrahedron Lett., 5,2010,2748-2750.

[33] GKS Prakash, T.Mathew, C.Panja, S.Alconcel, H.Vaghoo, C.Do and GA Olah, Gallium (III) triflate catalyzed efficient Strecker reaction of ketones and their fluorinated analogs, Proc. Nat. Acad. Sci., 104,2007,3703-3706.

[34] Y.Wen, Y.Xiong, L.Chang, J.Huang, X.Liu and X.Feng, Chiral bisformamides as effective organocatalysts for the asymmetric one-pot, three-component Strecker reaction, J. Org. Chem. , 72,2007,7715-7719.

[35] MM Mojtahedi, AM Saeed and T.Alishiri, Superparamagnetic iron oxide as an efficient catalyst for the one-pot, solvent-free synthesis of $\alpha$-aminonitriles, Tetrahedron Lett., 50,2009,2322-2325.

[36] M.R.Saidi and N.Azizi, A Novel and Efficient Method for the Synthesis of $\alpha$-Aminonitriles by the Reaction of Aminals with Trimethylsilyl Cyanide Catalyzed by Iodine, J. Iran. Chem. Soc., 1(2), 2004, 136-140.

[37] R.Sajeeva and M.Raghu, p-Toluenesulfonic acid catalyzed rapid and efficient protocol for one-pot synthesis of a-amino nitriles, Indian J. Chem., 47B, 2008,1572-1577. 
[38] B.M.Fetterly, N.K.Jana and J.G.Vercade, An efficient homogeneous and solid - supported promoter for aza and thia - Michael reaction and for Strecker reactions, Tetrahedron, 62,2006,440-456.

[39] E.Rafiee, A.Azad and M.Joshaghani, K5CoW12O40.3H2O: Highly Efficient Heterogeneous Catalyst for the Synthesis of $\alpha-$ Aminonitriles, Lette. Org. Chem., 4,2007,60-63.

[40] F.Cruz-Acosta, A.Santos-Exposito, P.de Armas, F.Garcia-Tellado, Lewis base-catalyzed three-component Strecker reaction on water. An efficient manifold for the direct $\alpha$-cyanoamination of ketones and aldehydes, Chem. Commun. , 4,2009,6839-6841.

[41] D.Bandyopadhyay, J. M.Velazquez and B.K.Banik, A truly green synthesis of $\alpha$-aminonitriles via Strecker reaction, Org. and Med. Chem. Lette.1,2011,1-11

[42] C.Li, Organic reactions in aqueous media with a focus on carbon-carbon bond formations, Chem. Rev., 105,2005,3095-3165.

[43] MM Mojtahedi, MS Abaee, H.Abbasi, Environmentally friendly room temperature strecker reaction: one-pot synthesis of $\alpha$ aminonitriles in ionic liquid, J. Iran. Chem. Soc., 3,2006,93-97

[44] G.Kumar, Preparation, coordination and structure of mixed ligand cobalt (II) complexes of histidine and hippuric acid, Chemistry, $18(2), 2009,130-136$.

[45] A.W.Parkins, Catalytic hydration of nitriles to amide, Platinum metals Rev., 40(4),1996,169-174.

[46] K.D.Surya, Cobalt (II) chloride catalysis one, pot synthysis of $\alpha$-aminonitriles, Beilstein J. org. chem., 1,2005, 8-9.

[47] Z.Szafran, R.M.Pike and M.M.Singh, Microscale inorganic chemistry (John Wiley and sons, New York,1991).

[48] D.Pavia, G.Lampman, G.Kriz and J.Vyvyan, Introduction to spectroscopy (Brooks/Cole CA USA, 2009).

[49] K. Nakamoto, Infrared of inorganic and coordination compounds (John Wiley and Sons Inc.,1997).

[50] A.B.P.Lever, Inorganic Electronic Spectroscopy (Elsevier, New York,1984).

[51] A.Cotton, Advanced inorganic chemistry a comprehensive text (John Wiley and sons, Inc1980).

[52] P.Surendra and A.K.Ram, Nickel (II) Complexes of Hydrazone of Isoniazid and their Magneto-Spectral, Electrochemical, Thermal Investigations Res. Lette. Inorg. Chem.35, 2008, 921-925

[53] M. Sunmez and M.Sekerci, Synthesis and Characterization of Cu(II), Co(II), Ni(II) and Zn(II) Schiff Base Complexes from 1amino-5-benzyl-4-phenyl-1-H-pyrimidine-2-one with Salicylaldehyde, Polish J. chem., 76,2002,907-914. 